\title{
Community mental health services: a vision for the future
}

\author{
Elaine Murphy
}

The nineteenth century asylum movement was the outcome of 50 years of campaigning by humane men of conscience who thought that they had found a solution both to providing care for people with mental disorders and also to curing them. Their efforts culminated in the 1845 Lunacy Act, which obliged all county councils to establish pauper lunatic asylums for the local population. There was almost universal agreement at the time about what needed to be done-a shared vision that fuelled the enthusiasm of politicians, social reformers, doctors, clergymen, and other influential people.

\section{Need for a new vision}

In the twentieth century we have abandoned the old vision, having recognised its serious limitations, but we have created no new alternative vision of community mental health care to inspire political action to turn vision into reality. At present, government is confronted by seemingly widely divergent opinions about the best route to successful mental health services. It responds to opposing factions by cautious appeasement of the various interest groups, giving a small grant here, a minor change in welfare benefit there. Government is unlikely to make substantial changes or agree to increased financial investment in the services until professional bodies, voluntary organisations, and the public authorities responsible for running the services unite with the service users and their families to demand with one voice the same things.

Moreover, the current differences of opinion between the various opposing pressure groups are more apparent than real. Conflicts are not about the fundamental objective of an improved local community based service but about the speed and energy with which hospital closures should be pursued, the best use of old buildings and land, and the real costs and affordability of good community alternatives. Unseemly interprofessional squabbles also hamper progress; these are about the appropriate roles for psychiatrists, general practitioners, nurses, psychologists, social workers, and the new "care managers." Interagency rivalries, too, lead to disagreements about which statutory authority should hold sovereignty over funds and take the leading responsibility for service planning. But underlying all this there is remarkable unanimity about the principles of community mental health care.

In the early years after the policy of community care was officially adopted by the government, two linked themes were emphasised in policy documents. The dominant theme was a plan for short term treatment of mental illness in district general hospital units, outpatient clinics, and day hospitals provided by the health service. The second theme, a much less forcefully presented one, was a plan whereby local government would provide a network of hostel and home accommodation, social work support, day care, and sheltered work for chronically disabled people, this latter so as to provide a real alternative to the back wards of the mental hospital. The first theme grew into a major symphonic work; the second theme was scarcely audible until the 1980s. What is now required is a redressing of this imbalance in developments and a clearer idea of the overall needs of individuals with mental disorder, whether they have transient problems or recurrent and chronic illnesses.

One key reason for the current poor quality of services for the most seriously disabled people is that health service resources have gradually shifted away from providing social aspects of care and been invested instead in acute psychiatric services staffed largely by professionals who perceive their role to be to assess, treat, and rehabilitate but not to provide or secure for patients the essential ordinary needs of life that every individual requires. The old mental hospital provided a home, occupation, friendships, and domestic and personal care, but in planning new services these aspects of the service have largely been neglected. In 1975 it was believed that these social aspects of care would be provided by local authorities, but they have received no transfer of resources from the health

Balance of spending in mental health services, England and Wales (source: Mental Health Foundation, 1990)

Service Percentage

Local authority community based services

Department of Social Security, sickness and invalidity benefit National Health Service ( $83 \%$ inpatient services)

service to allow them to do so. Health service money has been used mainly to develop district general hospital units, community teams of psychiatric nurses and other professionals, community mental health centres, and day hospitals and to increase the staffing levels of psychiatrists and nurses for acute catchment area services and also for assessment services for the growing number of elderly people with mental disorder. The table shows the balance of spending on mental health services; the figure shows the escalating costs of inpatient beds as numbers of beds have fallen.

\section{The needs of patients}

It is helpful to classify aspects of health and social care for individual patients along two dimensions; firstly, the ordinary needs of daily life that are common to all human beings, and, secondly, specific needs for treatment generated by the disorder itself - for example, antidepressant drugs, a course of electroconvulsive therapy, depot neuroleptic injections. Ordinary needs include personal care, domestic help, adequate personal income, a home of one's own, daily occupation and work, opportunities for leisure, personal friendships, and education. We need welfare benefits rights workers, housing and accommodation workers, support workers who provide domestic and personal "hands on" daily care, sheltered work and

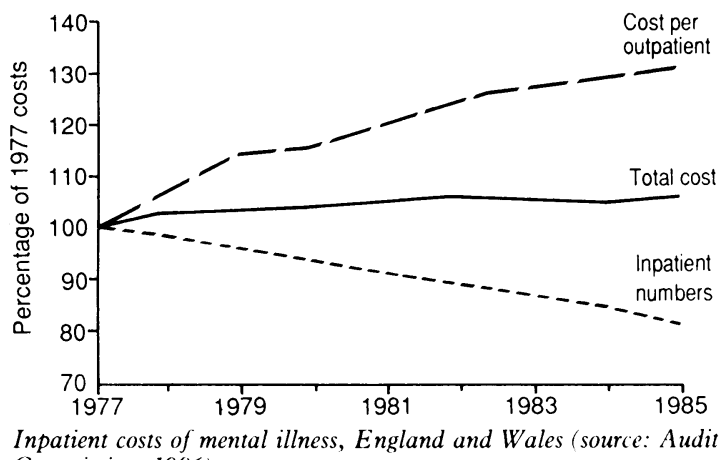
Commission, 1986
United Medical and Dental Schools, Guy's Hospital, Elaine Murphy, FRCPSYCH, professor of psychogeriatrics

BMF 1991;302:1064-5 


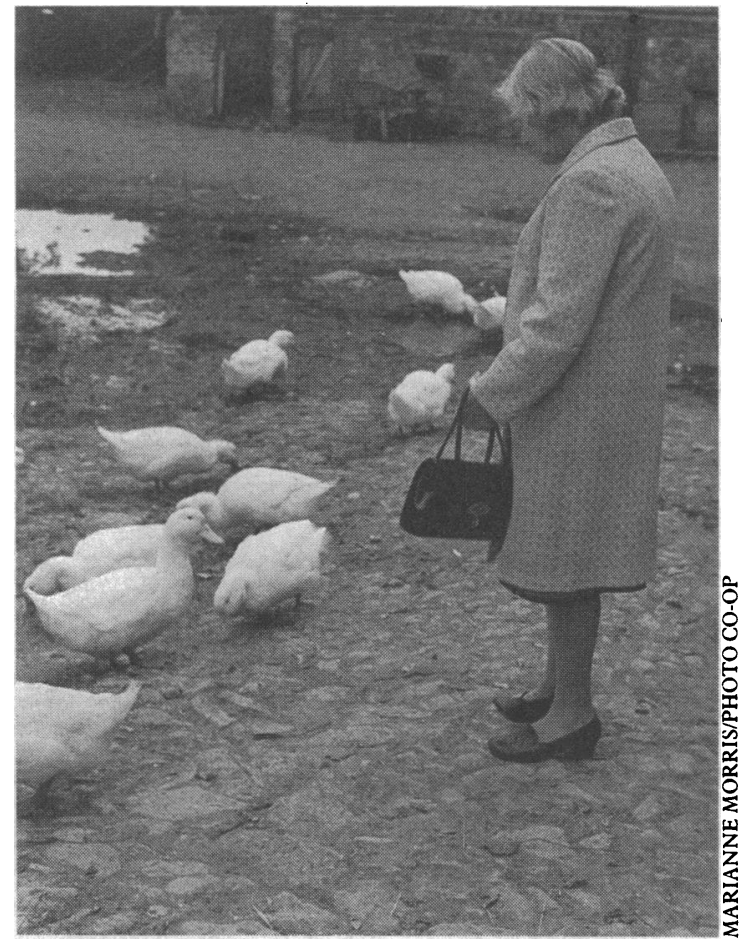

Ordinary needs of the patient include opportunities for leisure

work placement schemes, social and leisure clubs, and help for people to participate in the ordinary activities that people enjoy-shopping, going to a pub, the cinema, and so on.

A workforce that was competent to provide support in these areas would not be composed of doctors and nurses and other expensive health care professionals. There would be a need for highly skilled people, but most of the workforce could be relatively unskilled workers vocationally trained on the job. It is crucial that the workforce understands mental health problems and is able to recognise the occasions when specialist psychiatric intervention is needed, and these skills are readily learned by well chosen, unskilled workers who are given adequate training - as many home support schemes for dementia sufferers and younger mentally ill people have shown. ${ }^{12}$ Northern MIND developed an interesting model for a local mental health service based on the principles outlined here and estimated that an average health district with 200000 population would need a workforce of 454 , of which only 50 or so (11\%) would be qualified professionals. ${ }^{3}$ The cost was estimated to be broadly comparable to current service costs.

Good specialist psychiatric services are needed to provide specific treatment at the right time, but the contribution that a psychiatrist can make personally to the overall care of an individual is relatively small. Patients do need one clearly identified person in the service who is readily accessible, to whom they can turn for unquestioning support, to provide a listening ear-but the sheer numbers of people in a district requiring this kind of support would seem to preclude this being provided by a consultant psychiatrist. In the average British health district, even if we were to recruit 28 general psychiatrists (which would bring the numbers up to the American level), the chances of them being able to provide a personal service for several hundred of the most needy patients with schizophrenia, recurrent affective disorders, and severe neuroses are negligible. The evidence from the United States suggests that having more psychiatrists merely means that more psychiatric time is spent with people with less disabling disorders, most of whom would be cared for in this country by the people best placed to do it - that is, general practitioners - rather than spent with the most seriously affected patients. Psychiatrists and nurses tend to concentrate on the treatable because they are trained to treat, but the need for continuing personal support is equally important for those who have residual untreatable or chronic disabilities.

The simple fact of the current demographic changes in the population will inevitably mean that there will be fewer young people entering the health care professions in the future. Perhaps sheer necessity will drive services to recognise the need to restructure the workforce to use a smaller number of professionals; to recruit people willing to do more direct, practical tasks; and to restructure the operational system of delivering care to people in the community along the proposed care management lines outlined in the white paper Caring for People.

\section{The current situation}

We now have a service that is equipped to provide medical treatment of short term episodes of mental disorder but very poorly equipped to provide a comprehensive service for those whose disorders impact on their ability to lead independent lives. What is required is a radical change in the use of existing financial resources to support aspects of care that have been neglected in the past. This will inevitably mean reducing the number of health care professionals so that funds are released for alternative aspects of care.

There are initiatives underway in parts of the United Kingdom which point in the right direction. City and Hackney Health Authority have led the way for many years with their long term support team of generic mental health workers and network of supported accommodation. ${ }^{5}$ Case management projects ${ }^{6}$ are now under way in Lewisham and North Southwark, Hastings, Nottingham, Bromsgrove and Redditch, Leicester, and Cambridge, the first four of these projects launched with the support of the Gatsby Foundation (a Sainsbury Family Trust) through RDP (Research and Development for Psychiatry). These new methods of working are beginning to influence thinking about service development.

Bridging funds are urgently required to complete the closure of mental hospitals, but we must also review the current use of health service resources to ensure that the balance between health care and social care takes into consideration the mental health needs of the total population. The local authority is rightly now charged with the responsibility for developing social care, but this function is clearly impossible without a substantial increase in resources. If new monies are not forthcoming on a large scale, as seems unlikely in the near future, then the resources currently used by the health service must be used more creatively.

Finally, a last point about the role of a psychiatrist. Psychiatrists will always essentially be clinicians, but psychiatrists need now to develop a broader notion of what clinical work comprises, to include a responsibility for improving patients' quality of life in all its aspects when it has been adversely affected by mental disorder.

1 Murphy E, ed. Home or away. London: Research and Development for Psychiatry, 1987.

Rich M, Ness M, Smyth T. Coordinating care for people disabled by long term mental illness living in the community. Psychiatric Bulletin 1989;13:290-1.

3 Richardson K. Locally based community care: a personal view. Psychiutric Bulletin 1989;13:287-90.

4 Department of Health. Caring for people: community care in the next decade und beyond. London: HMSO, 1989.

5 Turner TH, Lovett A, Ness $M$. What should community mental health workers do? Experience in an inner city support team. Psychiatric Bulletin $1990 ; 14: 661$-3

6 Clifford P, Craig T. Case management systems for the long term mentally ill: a proposed interagency initiative. London: Research and Development for Psychiatry, 1988. 